UNTAG Law Review (ULREV)

Volume 2, Issue 1, May 2018, PP 70-84

ISSN 2549-4910 (online) \& ISSN 2579-5279 (print)

http://jurnal.untagsmg.ac.id/indeks.php/ulrev/indeks

www.fakhukum.untagsmg.ac.id

\title{
DEFENSIVE MEDICINE AS A RESULT OF MEDICAL NEGLIGENCE A BRIEF OVERVIEW
}

\author{
Rozlinda Mohamed Fadzil, Asma Hakimah Abd Halim, and Ain Alya Ariffin
}

\author{
Lecture at Faculty Of Law, Universiti Kebangsaan Malaysia
}

\begin{abstract}
Medical negligence is a topic in tort law which has been widely discussed as good, affordable healthcare, is greatly related to a nation's proof of its valiant efforts to attain a developed nation from a developing status by providing state of the art health care available and affordable, to all levels of society. As a penalty in medical negligence, damages are met out to punish errant members of the medical fraternity by way of legal judgements in a court of law. In some circumstances members of the medical fraternity may also have their medical licenses suspended or revoked. Annually, medical negligence's claim rates are inherently high and are expected to rise in tandem with patients' awareness of their medical rights. Complication arises when the plaintiff in a medical negligence law suit face difficulties in trying to prove that the negligence really did occur. In obtaining access to medical records after a purported civil malpractice accusation, obstruction of justice is rife. They arise when blurred lines cross between obligation of doctor-patient confidentiality and the need to disclose patient's medical records in order to securely obtain accurate sworn testimony of other medical practitioners. It is on the shoulders of the plaintiff, which in most medical malpractice law suits, rests on the patient (patients to the defendant doctors), to prove on a balance of probabilities that the breach of the duty of care did occur and from that breach, negligence had emerged, bringing about the claimed harm resulting in inherent damages suffered. High cost of litigation is also a common effect in medical malpractice law suits. This inevitably raises the insurance premium costs of all medical professionals, in general. These factors serve as impediments towards the plaintiff in obtaining justice. Hence, this paper will try to analyse the causes that has led to some of these problems. Also what will be the undesired effect caused by the difficulties in trying to prove that a medical malpractice has indeed occurred? The initial hypothesis to the matter is that it will cause negative effects to the livelihood of a patient's life and seriously hider access to medical care. This paper will however only be focusing on one popular but ill-favouredeffect that is greatly deliberated on when medical negligence is discussed, which is defensive medicine. Defensive medicine is actually a reaction culminating from the fear of medical malpractice lawsuits by medical practitioners. Fear of facing or being taken action upon, has caused them to take necessary safe steps which is to practice defensive medicine to avoid such risk.
\end{abstract}

Keywords : Defensive medicine, Medical, Negligence 


\section{INTRODUCTION}

Medical negligence is a serious issue in the medical field and has led to countless injuries on patients. Victims of such negligence may suffer serious injuries and in some extreme cases, even led to death. This confers the victims a right to claim compensation and in cases where death occurs, the next of kin, may claim rights to due process. This discussion will be looking at the aspects of proof in medical negligence. How far can patients prove that negligence has occurred and what are the difficulties in proving such negligence and what are its effects in the long run. Undoubtedly, this will greatly impact a person's life as it involves their health and livelihood. This paper will focus on one of the effect that has been greatly discussed in the field of medical negligence in Malaysia, which is defensive medicine. Gopal Sri Ram J in the case of Dr Soo Fook Mun v Foo Fio Na \& Anor ${ }^{1}$ has stated that:

...if the law played too interventionist a role in the field of medical negligence, it will lead to the practice of defensive medicine and the cost of medical care for the man on the street would become prohibitive without being necessarily beneficial.

This will help strengthen the argument that doubt and difficulties in proving medical negligence will give injurious implications to the victim. Highlight is given to the lacunae in this area of law which inevitably hinders the plaintiff from susceptibly proving that medical negligence has indeed occured. But, this lacunae, not only gives negative impact to the plaintiff, but also to medical practitioners because in the end, they themselves cannot expect what verdict will be given by the court. This fits in to medical negligence's nature which will always put both parties in the position where, when pitted against both parties, they would not know what the outcome of the case would be. ${ }^{2}$ Inevitably, these effects has continuously been occurring and has given negative impact to the medical world, shaking the very core of medical practice, which is cost of medical care.

\section{Defensive Medicine}

In a claim whereby the patient and doctor have uncertain chances of winning, both parties would be very much concerned with the possible outcome of the case and what liability will be

1 [2007] 1 MLJ 593.

2 Puteri Nemie Jahn Kassim \& Khadijah Mohd Najid, "Medical Negligence Disputes in Malaysia: Resolving through Hazards of Litigation or through Community Responsibilities?" 2013, Vol 7, No 6, International Journal of Social, Behavioral, Educational, Economic, Business and Industrial Engineering, p. 1758. 
imposed by the court. Hence, doctors will choose to play it safe by practicing defensive medicine. Defensive medicine is actually a reaction emanating from the unconfirmed precedence of medical malpractice suits and uncertainty due to present value of malpractice insurance in the medical industry. Fear of facing or being taken action upon has caused medical practicioners to take necessary safe steps which is to practice defensive medicine to avoid such risk.

Defensive medicine is defined as doctors performing unnecessary treatments on patients to avoid any possible negligence liabilities from being imposed upon them. ${ }^{3}$ Lawton $\mathrm{J}$ in the case of Whitehouse v Jordan ${ }^{4}$ defined defensive medicine as, "Performing procedures that does not provide any benefit on the patients, but only to save them from any potential medical negligence suit." Their rational is that the cost of defensive medicine is lower than that of the cost of facing a law suit, thus they choose the safer option. This solution will avoid any claim related to iatrogenic injuries (injuries related to medical treatment). ${ }^{5}$ Defensive medicine also includes doctor's refusal to give treatment. Because doctors are performing useless treatments to save themselves, it will surely give cause to negative effects, which starts a chain that usurps the element of cost in the medical practicing field, making it higher.

Defensive medicine exists in two modes which are positive and negative defensive medicine. The positive one is when a doctor provides for treatments which are cost ineffective, nonproductive, and even causes uncalled for risks. ${ }^{6}$ This shows that doctors tries to save themselves but by putting risks on patients. Examples of useless practices performed by doctors are diagnostic test, unnecessary treatments, admitting patients into the ward and much more serious, performing invasive procedures. $^{7}$ An evident significant gravity of defensive medicine, is seen from data from a North American data which is unavailable in Malaysia. The

3 K. Daniel and M. McClellan, "Do Doctors Practice Defense Medicine?" (1996) Quarterly Journal of Economics, p. 354.

4 [1981] 1 All ER 267.

5 Kessler, D. P., "Evaluating the Medical Malpractice System and Options for Reform." (2011) The Journal of Economic Perspectives $\square$ : A Journal of the American Economic.Association, https://www.ncbi.nlm.nih. gov/pmc/articles/PMC3 195420/ (3 Februari 2017).

6 Osman Ortashi et al., "The practice of Defensive Medicene among hospital doctors in the United Kingdom", (2013) BMC Medical Ethics, https://bmcmedethics.biomedcentral.com/articles /10.1186/1472-6939-14-42 (2 April 2017).

7 Duke Law Journal, “The Malpractise Medical Threat: A study of Medical Negligence” 1971:939, Duke Law Journal p. 945. 
Journal of the American Medical Association has released a statement that annually, almost 12,000 patients die from unneeded surgeries. ${ }^{8}$ Negative defensive medicine on the other hand is when a doctor refuses to treat a patient who has previous complications, patients in critical conditions and patients who have previously filed a claim against a medical practitioner. ${ }^{9}$ It can also happen when the doctor refuse to take the responsibility to treat the patient and refer him or her to other medical institution or medical practitioner. ${ }^{10}$

Other than that, their decision to practice defensive medicine might be because of concerns of these risks. The first risk is misdiagnosing the patient and second is conducting the wrong treatment on the patient. These two concerns can come together or separately but in the end, it will still put the doctor on alert, very nervous and capricious. An inherent effect to these discernible situation. Barnett $v$ Chelsea \& Kensington Hospital Management Committee ${ }^{11}$ is one of the most prominent case that can be used as an example in portraying a doctor's failure to treat a patient. In this case, three men sought medical treatment from the hospital but instead were told to go home and to seek attention from their respective general practitioner (GP) doctors. One of them died within a few hours due to arsenic poisoning. Even though plaintiff in this case failed to prove that the failure to treat has contributed to the deceased's death, but we can see that the doctor was still summoned to the court due to failure to treat the patients. Wilsher v Essex Area Health Authority ${ }^{12}$ is an example of a doctor's mistake in providing treatment. The fact of the case exemplifies this. A baby who was in the care of the hospital was administered an excessive amount of oxygen by an inexperienced doctor. This happened because the doctor made a mistake in reading the baby's oxygen level when he inserted the catheter in the baby's vein and not his artery. The baby was left blind in consequence.

Defensive medicine does not only occur in one area of medical specialisation only. Harvard Medical School ${ }^{13}$ in their studies has found that majority of doctors, regardless of the area of medical specialisation, have been found to practice defensive medicine. In Pennsylvania,

8 J. Thomas, "The Effect of Medical Malpractice", (2010) Annals Of Health Law Advance Directive http://www.luc.edu/ media/lucedu/law/centers/healthlaw/pdfs/advancedirective /pdfs/issue4/thomas.pdf (5 Febuari 2017).

9 D.M. Studdert, "Defensive MediceneAmong High-Risk Specialist Physicians in a Volatile Malpractice Environment”, (2005) Vol 293 No. 21 Journal of American Medical Associationp. 2616.

10 A. John \& H.K. Ellen, "Defensive Medicene: Effect on Costs, Quality, and Access to Healthcare" (2013) Vol 3 No.6Journal of Biology, Agriculture and Healthcare p. 30.

11 [1968]2 WLR 422.

12 [1987] QB 730.

13 K. Daniel and M. McClellan, “Do Doctors Practice Defense Medicine?” p. 353. 
Studdertet al. in their research on 824 subjects have found out that $42 \%$ of medical practitioners across the branch of medical practice refuses to treat patients who have high complications or which require them to perform high risks procedures. $92 \%$ of them stated that they ordered for tests, consultations and imaging to obtain concrete proof. Another $43 \%$ ordered for unnecessary imaging. ${ }^{14}$ This is not astonishing for those who are in the field as since 1930, Peabody F. W. ${ }^{15}$ has predicted that there will be activities of wasteful usage of the laboratories by the doctors. On another note, Frakes M. in his research of obstetric ${ }^{16}$ has examined the effects of setting a maximum liability on the doctors or economic caps or limits. He has seen a decrease in numbers of admitted patients as much as 3.9\% when such economic caps were implemented. The application of episiotomy also decreased at the rate of $11 \%$. His conclusion from the study was a finding that doctors certainly practice defensive medicine and take such precautionary steps as stated above to avoid high cost suits.

Defensive medicine may certainly bring about positive effects to doctors who aims to target avoidance of any mistake in providing treatments. But at the same time, by enlarge, it brings about bad outcomes to patients and the health care services, as a whole. Even though some doctors gain profit and comfort from defensive medicine, other sections of the medical practice, i.e. the patients will bear the negative side effects. Some of these include the inability to access proper treatments, reduce quality of treatments and its higher cost. ${ }^{17}$ One of the negative cons, the inability to access proper treatment, its effect among others, includes wastage of time, depleting resources and mismanagement of hospital utilities that will inevitably coincidently occur. The required quantity of treatment that is supposed to be dispensable to the public will decrease ${ }^{18}$. At the same time, demand is still high resulting in the decrease of treatment qualities ${ }^{19}$. At the world's current economic state, any type of wastage is regretted. Intrinsically, it is due to these reasons, that countries that face difficulties in providing health care services for example, sub-Saharan Africa will continue to be in a downturn spiral and deny more of their people's access to this branch of their human rights ${ }^{20}$. In

14 D.M. Studdert, "Defensive MediceneAmong High-Risk Specialist Physicians in a Volatile Malpractice Environment", p. 2609.

15 D. A. Mark, "Bad Law, Bad Medicine"3 (3) American Journal of Law and Medicine, p. 296.

16 F. Michaels, "Defensive Medicene and Obstetric Practices", (2012) 9 (3), Journal of Empirical Legal Studies p. 479.

17 D.M. Studdert, "Defensive MediceneAmong High-Risk Specialist Physicians in a Volatile Malpractice Environment", p. 2610.

18 Duke Law Journal, “The Malpractise Medical Threat: A study of Medical Negligence”, p. 943.

19 A. John \& H.K. Ellen, "Defensive Medicene: Effect on Costs, Quality, and Access to Healthcare” p. 29.

20 A. John \& H.K. Ellen, "Defensive Medicene: Effect on Costs, Quality, and Access to Healthcare” p. 29. 
the context of negative defensive medicine, some doctors also deny patients' right to seek proper treatment. This is because some of its medical practitioners choose low premium insurance. This innately means less protection. As such, the solution is to minimize the scope of the treatment offered. For example, a radiologist no longer interprets mammograms. The task is given to others to avoid any liability. The effects of such practice are naturally felt upon by female patients. The negative impact will also be injurious to women who live in rural areas where alternative treatment are unavailable. Any refusal to provide treatment comes with great risk. In the context of negative defensive medicine, some doctors also deny patients' right to seek proper treatment. This is because some of its medical practitioners choose low premium insurance. This innately means less protection. As such, the solution is to minimize the scope of the treatment offered. For example, a radiologist no longer interprets mammograms. The task is given to others to avoid any liability. The effects of such practice are naturally felt upon by female patients. The negative impact will also be injurious to women who live in rural areas where alternative treatment are unavailable. Any refusal to provide treatment comes with great risk.

Next is the issue of increasing cost of treatment. Because of major concerns about the risk of being sued due to medical negligence, majority of medical practitioners choose to practice defensive medicine which undoubtedly causes the very sharp increase of medical cost. ${ }^{21}$ As a result, it is seen that amid all the chaos, the business of healthcare services is sometimes overshadowed with other motive. In order to offset rising costs, some medical practitioners would resort to take advantage of administering those unnecessary extra treatments in order to gain extra profit. Killing two birds with one stone, as the saying goes. An example for this matter can be seen in China. In this current era, the hospital's budget has been drastically cut making the hospital as an institution, a profit based organization instead of one which caters for people from all social levels. Hence, profit is given more priority rather than the original purpose which is to treat and care for the patients' safety. ${ }^{22}$ The discussion on this matter will continue on to see what are the implications that will arose when the healthcare services no longer serve its original purpose but instead, focuses on maximizing profit gains. ${ }^{23}$

21 M SonalSekhar and N Vyas, "Defensive Medicene: A Bane to Healthcare", 2013, Annals of Medical and Health Sciences Research, https://www.ncbi.nlm.nih.gov/pmc/articles/PMC3728884/ (15 April 2017).

22 Ding Chunyan, Medical Negligence Law in Transitional China, Intersentia Publishing Ltd., Cambridge, 2012, p. 21.

23 Ding Chunyan, Medical Negligence Law in Transitional China, p. 21. 
Implication of shift of purpose of health institutions in China include;

i. Doctors are advised to look at patients' finances and offer treatments using the latest and most expensive technology. Some institutions provide bonuses and incentives based on the income brought in by the doctors. Doctors are given rewards or even profit sharing incentives when they over utilize technology utilities and prescribe unnecessary medications so that the hospital may claim for higher payment. ${ }^{24}$ Examples of commissions brought in by doctors are, $15 \%$ from selling western medicines, $20 \%$ from selling traditional Chinese medicines and $30 \%$ from the utilization of diagnostic procedures. $^{25}$

ii. Supply of medicines that brings about high profit rate.

Jin Yong Hong in his research has found that 20 to 30\% of hospital's profit comes from these practices and have deceived almost $70 \%$ of the patients. ${ }^{26}$ The drive to gain extra profit has caused doctors in China to perform high risk treatments. Some include high risk procedures such as organ transplant without properly qualified staff or suitable appliances. ${ }^{27}$ This portrays that defensive medicine is a one sided practice that causes lost to many parties and brings about risks that should not be taken lightly. This problem is also connected to the next effect that will be discussed, increasing insurance rate.

\section{Increase In Insurance Premium Rates}

As patients become more aware of their rights to proper, affordable and safe healthcare, most patients now opt to be protected partially or wholly by insurance. Even so, the type of treatment will still depend on the insurance premium paid. Commonly, in such situation, the usual norm that will occur is that the doctor will first have a look at how much coverage the patient's insurance covers, and then execute defensive medicine within such limits.

In an effort to obtain justice over the alleged negligence done, the patients and their families also face the risk of high litigation cost and the unknown probability that the lawsuit, may or may not fail. ${ }^{28}$ When the medical treatment and litigation cost are combined together, it is

24 Wang Chaoyinget. al, "Management of Hospitals Should Reflect the Public Interest" (2006) 7 Chinese Health Economics, p. 67.

25 Liu Dianen, "Clinical Decision and Health Policy” (2005) 9 Medical and Philosophy, p. 10.

26 JinYonghong, "Who Caused the Over-supply of Health Care" (2005) Jian Kang Bao, p. 3.

27 Ding Chunyan, Medical Negligence Law in Transitional China, p. 33.

28 Ding Chunyan, Medical Negligence Law in Transitional China, p. 33. 
distinctively possible that the plaintiff would be put in a more difficult position financially. Things would get worst in the event that they do not have any medical insurance to cover emergency eventualities. Thus, by looking at some of these difficulties that the patients faced to prove and win a medical negligence suit, it is apparent that they are exposed to high risk of financial expenditure if the negligence undoubtedly had occurred. Nevertheless, notwithstanding the actuality of whether a negligence malpractice lawsuit is in the end, able to be proven successfully or not, the lawsuit cannot even initiate, let alone be proven properly in the absence of a medical insurance.

As a consequence of this scenario, this paper will also take a look into the scope of health insurance and medical practitioner's insurance. This matter is not only of the patients' concern but also of the doctors'. Doctors are advised to get insurance in order to protect them from medical negligence. But one of the challenges to policy holders is that each year, insurance policies premiums raise drastically. This in fact puts on a heavy burden on the medical practitioners. The patients are also affected because the cost of treatments will rise. The diagram below shows the implication of medical negligence that will in turn affect the cost of medical treatment. ${ }^{29}$

Table 1.1 Flow chart of the effects of medical negligence

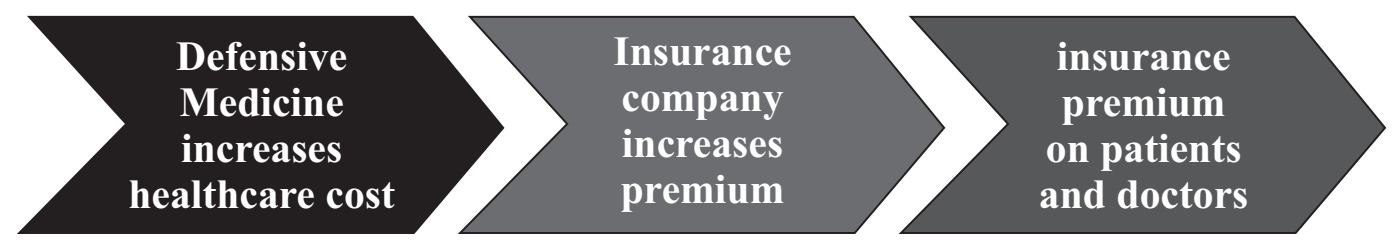

A doctor's insurance premium is different according to the respective medical specialization branch. Irrespectively, insurance premium are most often expensive and continues to rise every year. Based on the data provided by the Malaysia Medical Association ${ }^{30}$, the average increase is between RM 5,000 to RM 6,000 for gynecologist, RM 3,000 to RM 4,000 for surgeries, and RM2,000 to RM3,000 for orthopedic per year.

29 A. John \& H.K. Ellen, "Defensive Medicene: Effect on Costs, Quality, and Access to Healthcare” p. 31.

30 PuteriNemieJahnKassim\& Khadijah Mohd Najid, "Medical Negligence Disputes in Malaysia: Resolving through Hazards of Litigation or through Community Responsibilities?" p. 1780. 
The table below shows the increase in premium based on respective branch of medicine.

Table 1.2 Increase in doctor's insurance premium in multiple medicine branch.

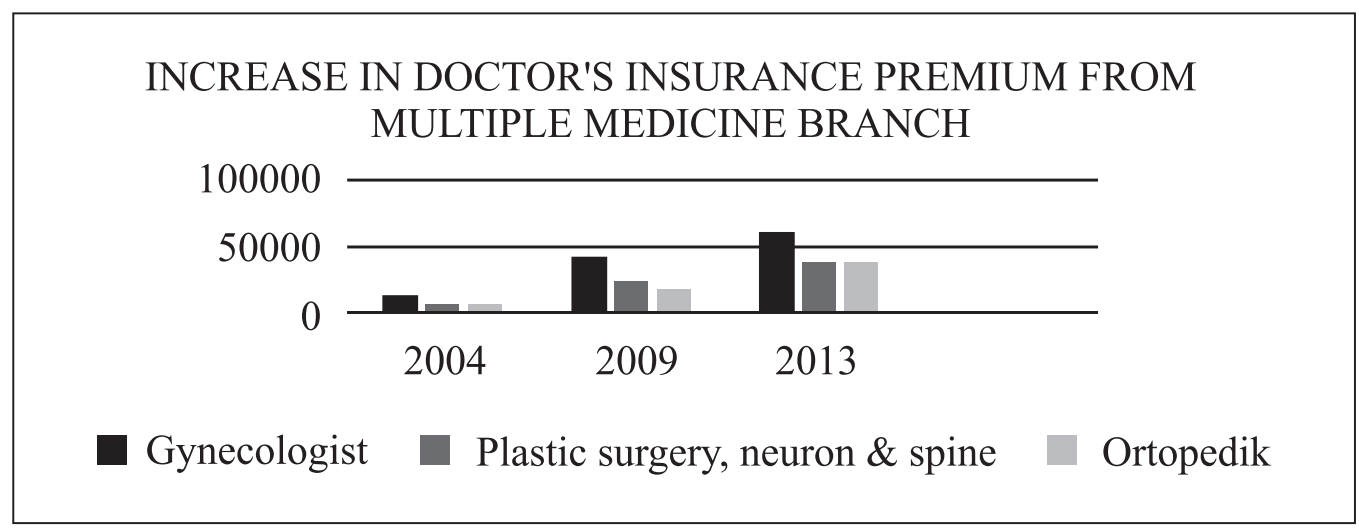

Source: Puteri Nemie Jahn Kassim \& Khadijah Mohd Najid: 2013

The protection provided to patients are different based on the amount of premium paid. The situation in Malaysia since December 2013 has shown that there is a significant increase in the insurance premium. This is because the Medical Association has asked for the medical fees in medical facilities to be increased as much as $30 \%$. ${ }^{31}$ But the increase that actually took place was of $20 \% .{ }^{32}$ Currently however, there are companies that have increase such fees up until $30 \%$. This percentage when translated into numbers, it is on average RM 180 per year. ${ }^{33}$

One of the most affected party in the impasse is the insurance company as they now have to provide for the same medical protection but at a higher price. Hence, they react by increasing the price of insurance premiums even though it is not applauded by the buyers. Astro Awani as a source has shown that in 2013 , the medical insurance has increased drastically. The increase is as followed. ${ }^{34}$

31 I. Lee, Malaysia Sees Sharp Increase In Health Insurance Premium, 2014, https://www.imoney .my/articles/malaysia-sharp-increase-health-insurance-premium (10April 2017).

32 Christina, "Medical Premiums Up Again”, The Star Online, 27 November 2016, http://www.thestar.com.my/news/nation /2016/11/27/medical-premiums-up-again-rising-healthcarecosts-are-to-be-blamed-agents-and-policyholders-told/ (1 April 2017).

33 C. Christina, "Insurance Up, Again", The Star Online, 27 November 2016, http://www.thestar. com.my/news/nation/2016/11/27/insurance-up-again/ (1 April 2017).

34 Anon, "Kos rawatan perubatan di Malaysia", Astro Awani, 2013, http:/www.astroawani.com/ infografik/kos-rawatan-perubatan-di-malaysia-23035 (5 April 2017). 
i. Insurance premium of policy holders increases by $50 \%$ to $100 \%$ if the policy holder is already ill.

ii. Allowance for being admitted in wards increases by $50 \%$.

This now brings about inflation because it is linked to defensive medicine which exploits insurance companies, to the max. For example, in the United States, the expenditure for this matter cost about USD 4.2 billion to USD 12.7 billion annually. As a result, insurance companies now shift the burden to the policy holders even though it is only payments for useless additional medical procedures. In situations where patients are unable to pay such amount, the hospitals and the country's economy are burdened. In more extreme cases, hospitals might opt to decline treatment to such patients. A case actually took place in China. The Wang Jian Min $^{35}$ case occurred in Beijing where the patient died in the hospital's corridor. The hospital declined to treat this patient who was suffering from abdominal pain and vomiting blood as he could not advance the medical fees. He died outside of the Tongreng Beijing Hospital's emergency department while waiting for his friend to try and gather the needed fees. Another case that had occured in China of a similar nature is when a boy was abandoned in a field by the hospital which then died due to starvation. ${ }^{36}$ Malaysia is still fortunate for not sinking into such critical level as was seen in China.

The increase of insurance premium causes significant impact at different rates depending on the age and health of respective patients. The illustration below shows the increase in premium by $20 \%$ for a patient who is in his $30 \mathrm{~s}^{37}$

35 Anon, "Man Without Money to Pay Medical Expenses Dies in Hospitals", The Beijing News, 15 Disember 2015, http://news.xinhuanet.com/society/2005-12/15/content_392377.htm(1 April 2017).

36 Anon., "Hospital refuses to Treat Boy Who is Unable to Afford Medical Expenses", Hua Shang Bao, 15 Ogos 2014, http://news.sina.com.cn/s/2004-08-15/09013395586s.shtml. (1 April 2017).

37 I. Lee, Malaysia Sees Sharp Increase In Health Insurance Premium, 2014, https://www.imoney .my/articles/malaysia-sharp-increase-health-insurance-premium (10April 2017). 
Table 1.3 Premiums for RM 100,000 worth of protection per year

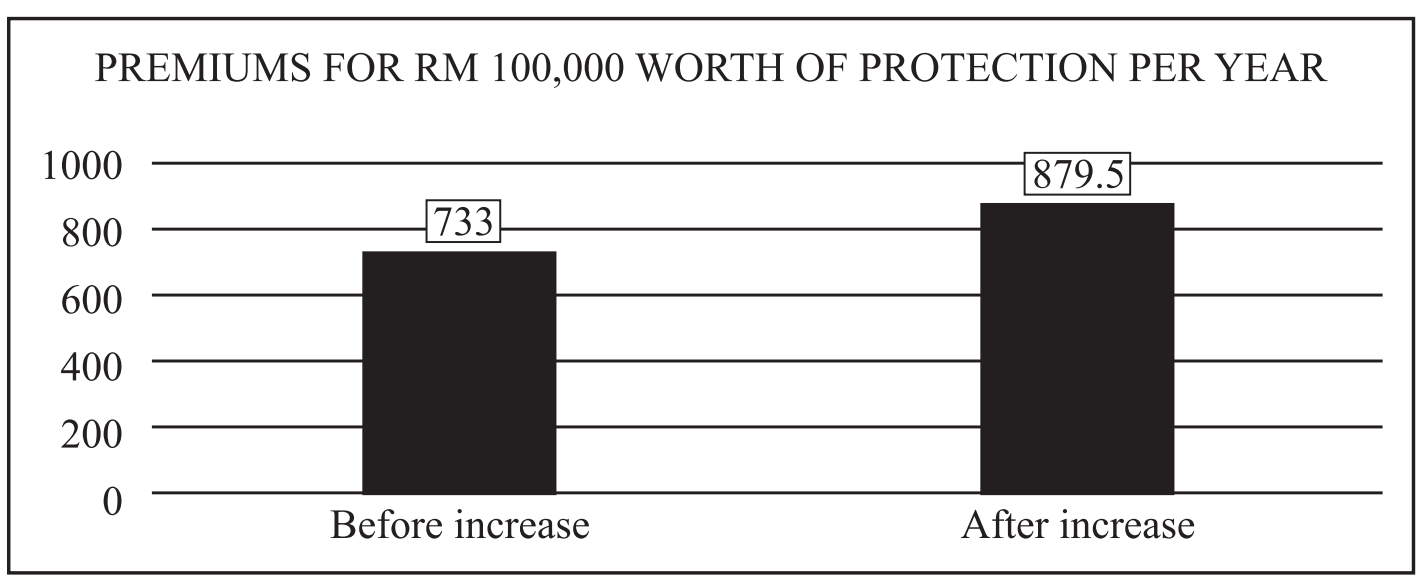

In line with such increase, senior citizens will also feel the burden of such high premiums when the increase in fee go up to RM 100. The basic rule is that the older the person is, the higher his insurance premium. $^{38}$

A debate on such matter has actually occurred before. James Fong, the president of NAMLIFA (National Association of Malaysian Life Insurance and Family Takaful Advisors) questioned the rational of insurance companies in increasing the premium rates. He does not agree with such increase and is of the opinion that with the rate of mortality and life span these days, the premiums should be lower and not vice versa. This shows that there are irregularities in the insurance payment system. He also pointed out the effect of such increase to the national bank's strategy in decreasing the government's expenditure. The national bank has a target that by the year 2020, 75\% of the people in Malaysia would have their own medical insurance. ${ }^{39}$ In return, the government need not build too many new hospitals. But due to such increase, it is foreseeable that patients would continue to rely solely on government hospitals and avoid buying private insurance.

After analyzing the country's insurance market, it is obvious that the current and new policy holders do not hold such capacity in keeping to pay more and more of the increase in premiums in the future. Because of such uncertainty in proving medical negligence and the implementation of defensive medicine, this matter is hard to avoid. These problems are

38 I. Lee, Malaysia Sees Sharp Increase In Health Insurance Premium, 2014, https://www.imoney .my/articles/malaysia-sharp-increase-health-insurance-premium (10April 2017).

39 C. Christina, "Medical Premiums Up Again”, The Star Online, 27 November 2016, http://www.thestar.com.my /news/nation/2016/11/27/medical-premiums-up-again-rising-healthcarecosts-are-to-be-blamed-agents-and-policyholders-told/ (1 April 2017). 
interrelated and we must solve the underlying issues first, in order to eradicate further problems.

\section{Financial Burden}

Defensive medicine and the increase in insurance premiums are two examples of implications that arise when there is uncertainty in the parties' quest to prove their respective cases. But because the matter is of a very serious nature, there are more adverse effects that may ensue that will be further discussed.

The most prominent effect is financial burden. The process of commencing a suit is not an easy task. Various processes and stages are to be implemented, wading through processes is burdensome, involving a lot of parties. A negligent suit can take up until twenty five years. ${ }^{40}$ Added with the need to obtain expert witness, amongst doctors in the respective medical field. The cost of expert witnesses is high. Not just that, there will be volumes of documentation matters, tedious legal court procedure and intrinsic bulky undertaking such as obtaining patient's medical record from the hospital. This will incur extra costs and require abundance of personal perseverance. If the plaintiff has a strong case, he will be awarded the damages sought after.

Not with standing the above, the civil system in awarding tortious damages has been criticized for being unsatisfactory. The final amount awarded in medical negligence suits will then decrease as the plaintiff needs to pay administration fees ${ }^{41}$ as stated above. Lawyer's fees are also taken out from the pot. The Chairman of the Consumer Association of Pulau Pinang, S. M Idris stated that for every 1 medical negligence case reported, another 10 goes silent. One of the reasons for this is because the victim is not financially capable to get the justice they deserve. At the same time, the victim may suffer from physical or emotional damage. In a worst case scenario, it may be both. Some adverse effects include permanent damage, loss of employment and loss of wage for self-sustainability. ${ }^{42}$ As for surviving victims, their medical cost are

40 Foo Fio Na v Hospital Assunta \& Anor [1999] 6 MLJ.

41 PuteriNemieJahnKassim\& Khadijah Mohd Najid, "Medical Negligence Disputes in Malaysia: Resolving through Hazards of Litigation or through Community Responsibilities?" p. 1758.

42 T. Jonathan, “The Effect of Medical Malpractice", 2010, Vol 19, Annals Of Health Law Advance Directive, p. 306 . 
incurred in some instance continuously, for the rest of their life. As with the current economic situation, the cost will continue to rise annually. A study done in Florida on 127 families $^{43}$ has shown that $24 \%$ of them have to incur medical cost for a long period of time. An example of cost incurred in a case of medical negligence is outlined here as seen in Lim Swee Chin v Joseph A/L David ThangakasGuamanSivil No A53KJ-251-09-2014;

i. Medical report from Melaka General Hospital cost RM 40. Specialist report from Mahkota Orthopedics Hospital cost RM 550.

ii. Report from the police and the Ministry of Transport cost RM 22.

iii. Cost of expert witness for the plaintiff ( Jeyaratnam a/1 T. Satkunasingam, ortophedic specialist of Mahkota Medical Centre, Melaka) is RM 1500.

iv. Other witness' cost (plaintiff's employer) is RM 100.

v. Physiotherapy for the broken left wrist is RM2,160 at the government hospital.

vi. Physiotherapy on weakness of left hand muscle on the scale of $4 / 5$ at the government hospital is RM 260.

\section{CLOSING}

Based on the discussion above, it is clear that when doctors are placed in an uncertain and bleak situation especially one that involves increased premium insurance costs and a possible tarnish to their good name bringing about future prospects of them losing their medical licenses, defensive medicine is commonly practiced. This practice actually then brings about more harm to the patients. In the end, the pressure falls back on the patient's shoulders and it is as if everything goes back to square one in the quest to combat medical negligence. The litigation system for medical negligence needs to be upgraded as soon as possible.

\section{Proposed Further Research}

Newly funded research must be carried out in future to help in the quest to solve this issue. These are some of the area of research that desperately needs a serious overhaul done to ascertain the viability of such proposed betterment schemes: First, should a no-fault compensation scheme be practiced in Malaysia? Second, there must be a research on what medium is suitable for patients to keep their own medical records. A few countries in Europe 
have implemented virtual storage and smart cards for such purposes. Gathering of such data through interviews with the people in the industry must be done to see if the proposed changes meets set criteria of the proposed research. This is to analyze the matter from the practical side of the matter. Proposed changes to be undertaken must be widely analysed. Input from law makers, NGOs and the general public must be taken into consideration. Data from a wide range and scope will be of great benefit to the study.

\section{Reference}

Anon, "Man Without Money to Pay Medical Expenses Dies in Hospitals", The Beijing News, 15 Disember 2015, http://news.xinhuanet.com/society/200512/15/content_392377.htm(1 April 2017).

Anon., "Hospital refuses to Treat Boy Who is Unable to Afford Medical Expenses", Hua Shang Bao, 15 Ogos 2014, http://news.sina.com.cn/s/2004-0815/09013395586s.shtml. (1 April 2017).

C. Christina, "Medical Premiums Up Again", The Star Online, 27 November 2016,http://www.thestar.com.my/news/nation/2016/11/27/medical-premiums-upagain-rising-healthcare-costs-are-to-be-blamed-agents-and-policyholders-told/ (1 April 2017)

Ding Chunyan, Medical Negligence Law in Transitional China

I. Lee, Malaysia Sees Sharp Increase In Health Insurance Premium, 2014, https://www.imoney.my/articles/malaysia-sharp-increase-health-insurance-premium (10April 2017)

JinYonghong, "Who Caused the Over-supply of Health Care" (2005) Jian Kang Bao

Liu Dianen, "Clinical Decision and Health Policy” (2005) 9 Medical and Philosophy.

Puteri Nemie Jahn Kassim \& Khadijah Mohd Najid, "Medical Negligence Disputes in Malaysia: Resolving through Hazards of Litigation or through Community Responsibilities?” 2013, Vol 7, No 6, International Journal of Social, Behavioral, Educational, Economic, Business and Industrial Engineering

T. Jonathan, "The Effect of Medical Malpractice", 2010, Vol 19, Annals Of Health Law Advance Directive 
Rozlinda Mohamed Fadzil, Asma Hakimah Abd Halim, and Ain Alya Ariffin : Defensive ....

Wang Chaoyinget. al, "Management of Hospitals Should Reflect the Public Interest" (2006) 7 Chinese Health Economics. 